This is an open access article under the CC BY-NC-ND license

Issue IV, 22 November 2021

e-ISSN 2707-9481

Institute of Metallurgy and Ore Beneficiation, Satbayev University, Almaty, Kazakhstan

ISBN 978-601-323-252-2

https://doi.org/10.31643/2021.01

\author{
Aydana Alimzhanova \\ Karaganda Technical University, \\ Karaganda, Kazakhstan \\ E-mail: halidok_09_95@mail.ru \\ ORCID ID 0000-0002-7179-7227
}

\author{
Khalida Kadylbekova \\ Karaganda Technical University, \\ Karaganda, Kazakhstan \\ E-mail: kadylbekova.halida@mail.ru
}

\title{
Processing the results of space observation of the processed areas of Karaganda
}

\begin{abstract}
The article is devoted to the development of a method for tracking deformation in the underworked territories of Karaganda based on the data processed by radar images from the ENVISAT satellite. The article provides an overview of the use of modern radar satellite systems. The step-by-step search of archival data on the territory of Karaganda in the Eoli-sa program is described. The processing of radar images from the ENVISAT satellite for the period from 2003 to 2010 in the SARscape module of the ENVI software package is described in detail. Based on the processed data, graphs of dynamic processes were compiled. The analysis of the results of interferometric processing of radar data is performed. Traditional and modern methods of tracking the deformation of underworked territories are also analyzed.
\end{abstract}

Keywords: satellite radar interferometry, landscape changes, observation of geodynamic processes, radar data, processing of space images, motion interferomogram.

Cite this article as: Alimzhanova A.; Kadylbekova Kh. (2021). Processing the results of space observation

Of the processed areas of Karaganda. Challenges of Science. Issue IV, 2021, pp. 5-11. https://doi.org/10.31643/2021.01

\section{Introduction}

Today Kazakhstan ranks eighth in the world in terms of coal reserves. Coal mining creates voids in mountain ranges, which in turn causes movement of the earth's surface. The classical method of preventing the movement of the earth's surface, that is, filling voids with material, is rarely used in Kazakhstan due to its economic inefficiency, therefore, collapse of the earth's surface is common. In 2014 alone, similar disasters occurred in several cities of Kazakhstan: Ridder, Karaganda and Kokshetau. In the city of Karaganda, where the mines of the Karaganda region are located close to each other and, therefore, in the midst of large-scale mining operations, very dangerous subsidence processes occur.

Monitoring such topographic changes and geodynamic processes using traditional measurement methods such as leveling and total station is a laborious process. In addition, traditional control methods do not provide a complete picture of the processes occurring outside the profile lines or in hard-to-reach places. Satellite radar interferometry technology for observing such phenomena shortens the acquisition time between periods and allows an image of the rapid movement of the earth's surface at that moment. Its coverage area is $30 * 30 \mathrm{~km}$. Currently, foreign companies are engaged in radar interferometric survey in the Republic of Kazakhstan (Kainz Wolfgang, 2019; Kharchenko, 2017).

Satellite radar interferometry is a measurement technique that exploits the interference effect of electromagnetic waves. The essence of the method is the creation of an interferogram. An interferogram is a composition of two images of the same area, made by one satellite, and provides information about the phase and amplitude of the signal.

Among the areas of application of satellite radar interferometry data are the following:

- creation of a digital terrain model, including a high-precision one (samples with a spatial increase of about one meter and an accuracy of determining the height of 1-2 meters); 
- measurement of deformations to the nearest part of the radar wavelength;

- Determining the speed of a vehicle, such as a fast moving object.

In terms of price and quality, low magnification radar data (10-30 m - ENVISAT, ERS-2, etc.) are in great demand, while medium magnification radar data $(4-8 \mathrm{~m})$ have very good prospects. Such radar surveys are used to create digital terrain forms, mapping, monitoring the ecological state of the area, assessing seismic hazard, monitoring floodplains and areas with constant fog, as well as for solving many other problems in various fields of activity.

Unique tasks can be solved using high-resolution radar data (1-3 m). However, due to their relatively high cost, they are mainly in demand only when solving local problems. For example, high-resolution radar images can detect movement of the earth's surface, especially buildings and industrial structures, with very high accuracy. In this regard, the ability of high-resolution radar data to recognize objects and group them is significantly improved with the help of specialized software products such as SARscape (Morev \& Nezamov, 2018).

\section{Experimental part}

The Eoli-sa program was used to obtain data from the archives of the European Space Agency, i.e. for the selection of satellite images (Picture 1) [3].

Picture 1. Eoli - sa program interface

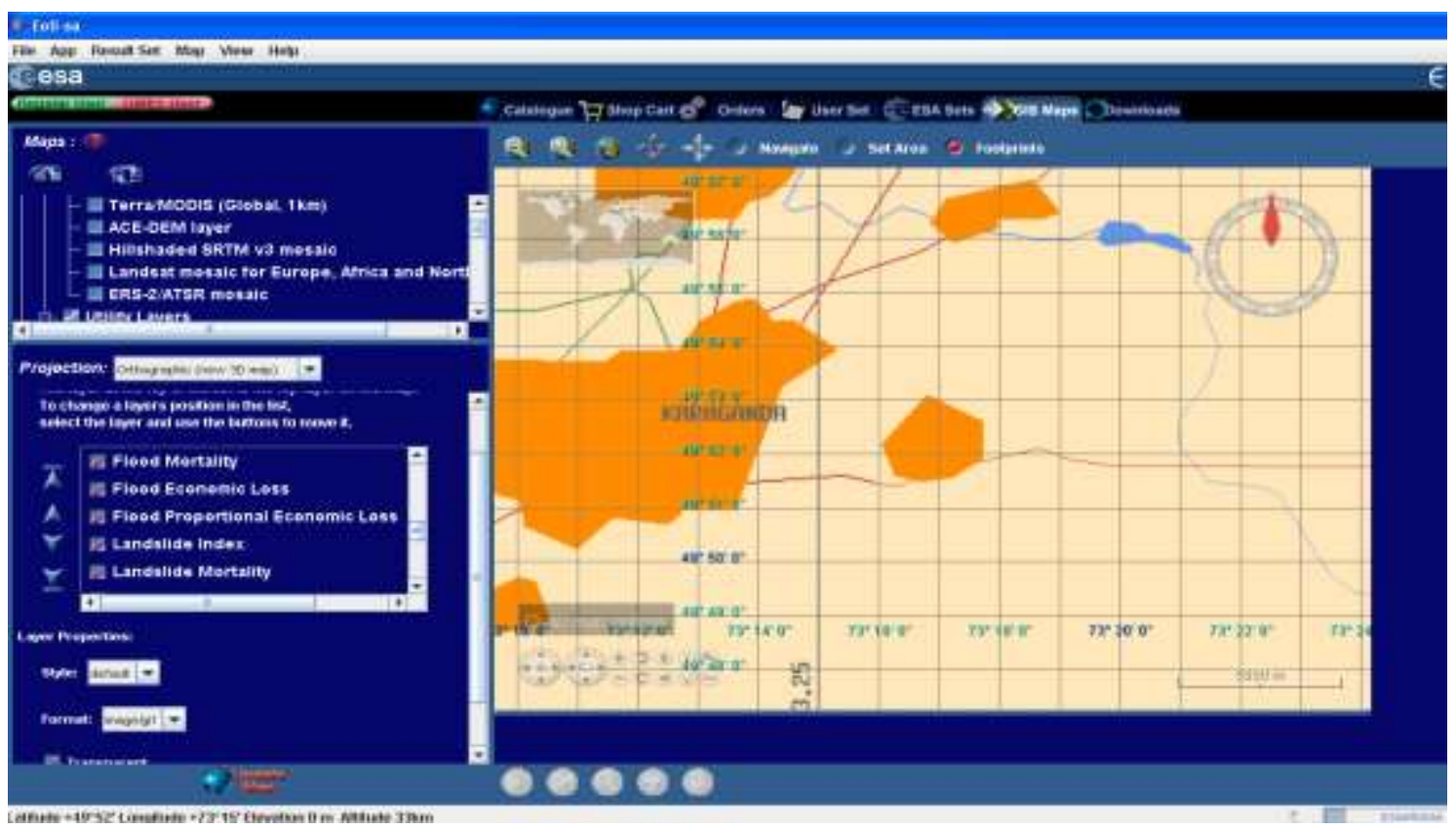

Eoli-SA is a free multi-platform interactive program. It allows users to access, order, and ultimately track their status in the Terrestrial Product Catalog. It also allows GSP, SCI and SPR operators to retrieve product data and metadata online. Product content is integrated into collections that can be easily queried and viewed (Tarasova, 2019).

Based on the analysis of the data in the archive, the ENVISAT satellite system was selected.

As a result of the search for information in the archives by the ASAR sensor in the Eoli-sa program, 29 images from 4 different tracks were found. To view and order satellite images, it is necessary to identify the ASAR Image Mode sensor and select the observation time. When choosing the time of observations, the period from 2003 to 2010 was taken into account. (Picture 2).

You can view the images identified in the search results by clicking the outline of an image on the map, clicking the image thumbnail to the right of the map, or selecting a row in the table. An example of an archived image is shown in Picture 3. 
Satellite images were processed in the SARScape module of the ENVI software package. This program was also acquired under the aforementioned grant project funded by the Ministry of Education and Science of the Republic of Kazakhstan.

Picture 2. Complete result of each image, taking into account the trajectory and track

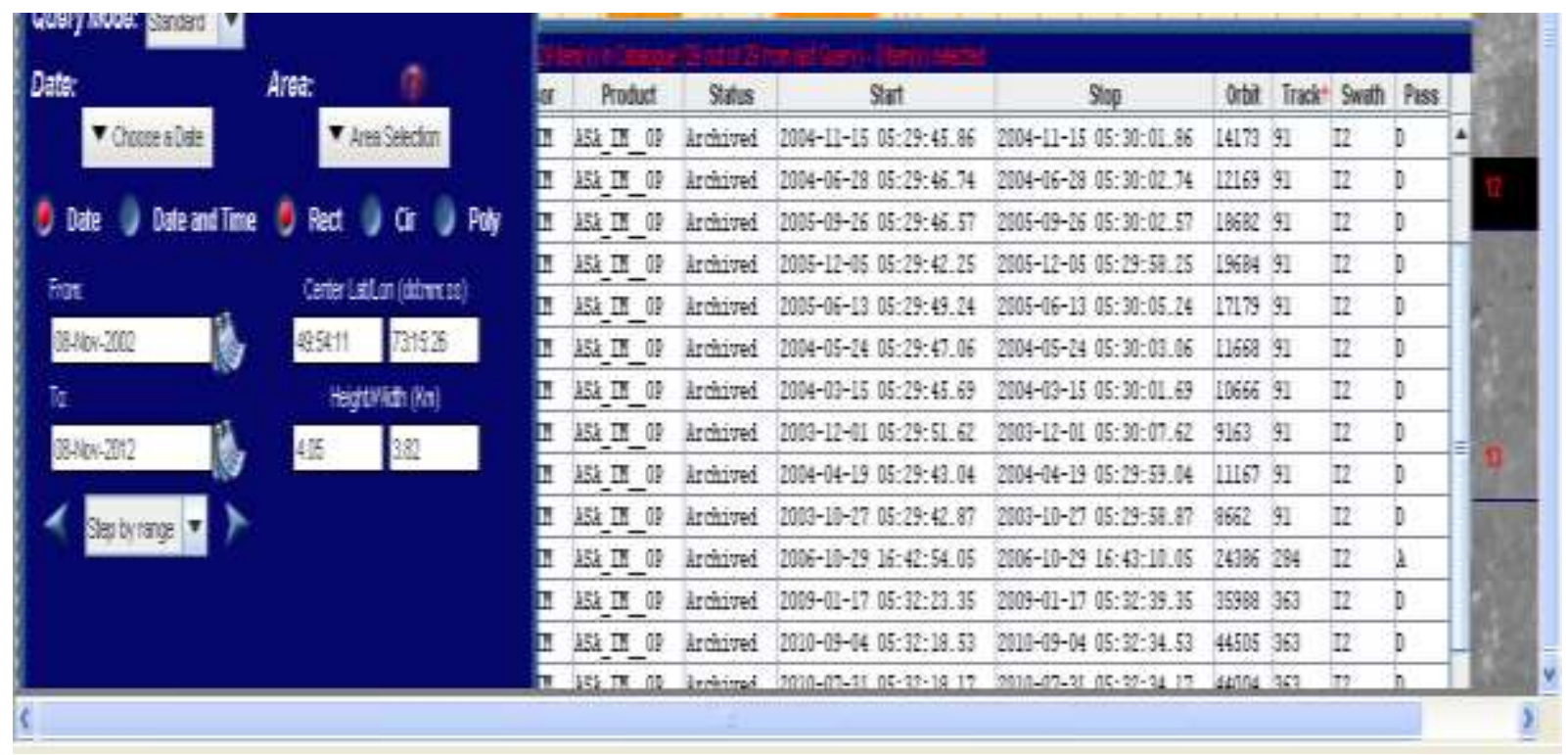

Picture 3. done on December 18, 2006 Archival photo of Karaganda

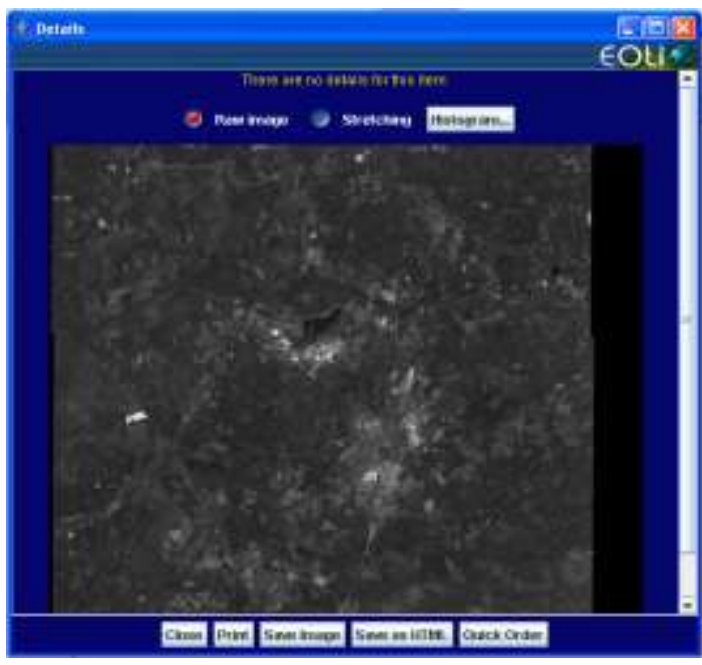

\section{The discussion of the results}

At the first stage of processing, ENVISAT satellite images were imported from the raw * .N1 extension to the ${ }^{*}$.cls extension and the baselines were processed. According to the research, i.e. satellite images of ENVISAT track 363, a graph of the dependence of the time factor on the critical base was built (Picture 4) (Kharchenko, 2017).

Save your file in WORD format, Calibri font, size 11, 1 spacing.

The second stage of processing is the selection of pairs for interferometric processing. Pairs were selected according to several criteria, i.e. of the total number of possible pairs. The time base is the interval between images of the interferometric pair (Kharchenko, 2017).

At the third stage of development, a quantitative terrain model was created. SRTM data in Kazakhstan has been increased by about 90 meters. Creation of the Karaganda SES on July 31, 2010 and 10/09/2010. ENVISAT - satellite imagery used. 
General data processing was carried out under the temporary license of the SarScape module. The licensor is the Sovzond company, the official distributor of the ENVI program in Russia. SarScape software is an additional module of the ENVI program for pre- and thematic processing of radar images. The interferometry module allows you to perform interferometric processing of radar data and, finally, to obtain a digital terrain model or earth displacement map.

Picture 4. Graph of dependence of the time factor of the satellite image ENVISAT track 363 on the critical base

Time-Baseline Plot

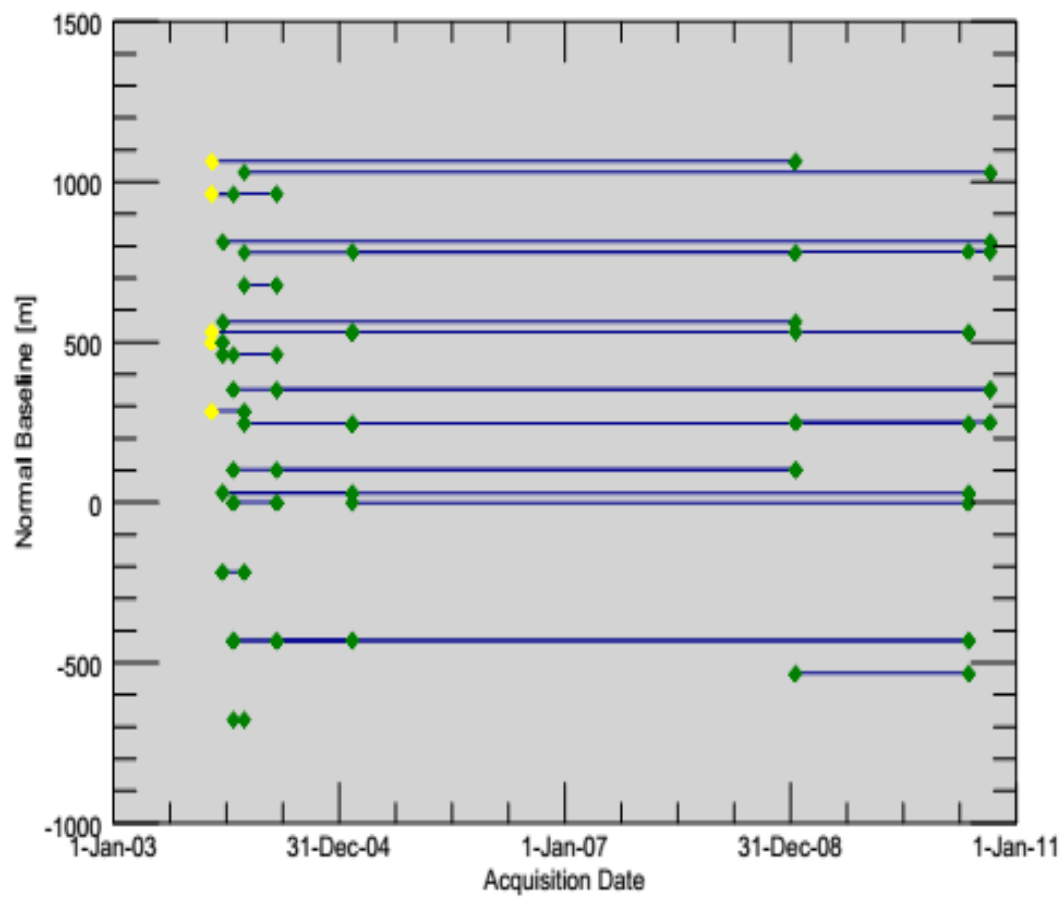

The main result of this work is a differential interferogram in the form of obtaining a synthesized phase of the terrain from a complex interferomogram (Morev \& Nezamov, 2018).

Based on the processing of pairs of radar images from the ENVISAT satellite, a map of the subsidence of the surface of civil and industrial objects, as well as areas of the location of mines in the Karaganda region and the Oktyabrsky district, was obtained.

Geocoding and calibration were carried out in relation to the digital terrain model of Karaganda, previously developed by the author. According to the results of processing and calculations, in urban areas there are both stable areas with small displacements, and areas with a real acceleration of the subsidence process.

The subsidence value is obtained from the drawings, and the subsidence graph is plotted at the points shown in the figure (Picture 5).

Picture 5. Territory
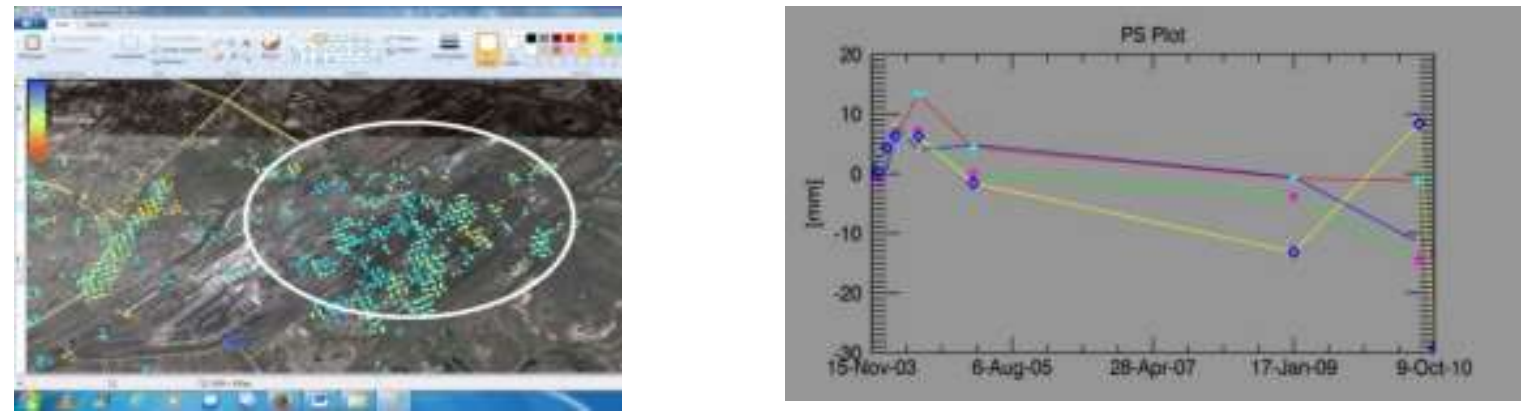
In 2013, a surface subsidence of $40 \mathrm{~mm}$ for the reporting period was recorded in the area of the chimneys of the chemical production of coke HU-1 (Picture 6).

Picture 6. Landslide in the area of pipelines
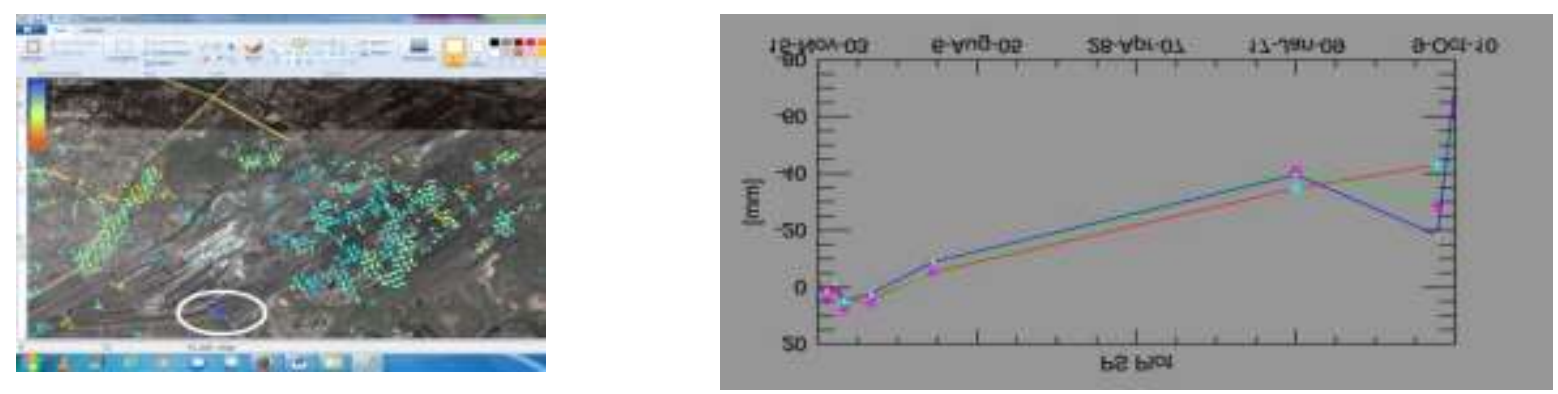

Due to the lack of mines and insufficient processing, the Maikuduk and Abai areas are in good condition (Picture 7.8).

Picture 7. Study of the subsidence process in the Abai area
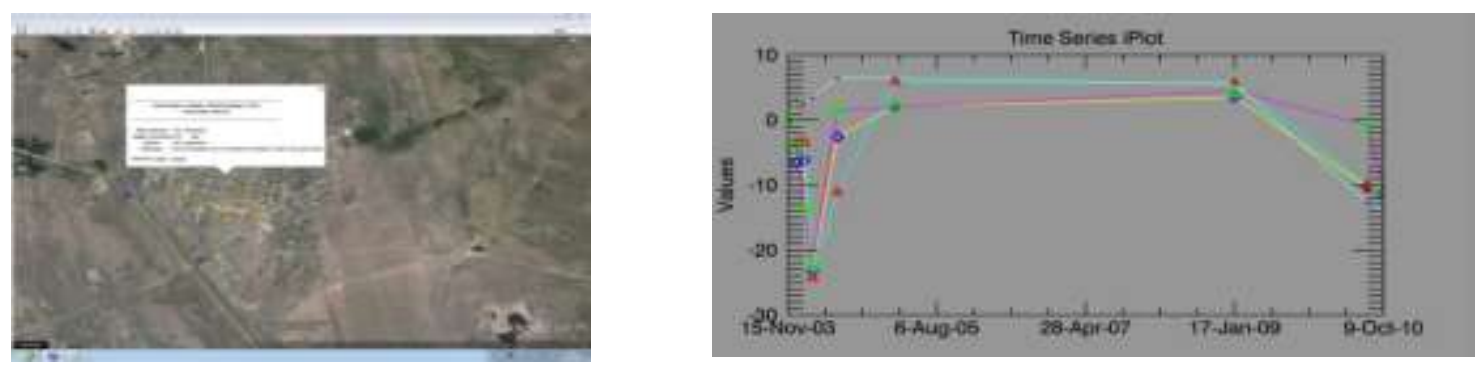

From 2003 to 2010, a slight subsidence of about $10 \mathrm{~mm}$ was observed in the Oktyabrsky district (Picture 8).

Picture 8. Oktyabrsky district - Maikuduk
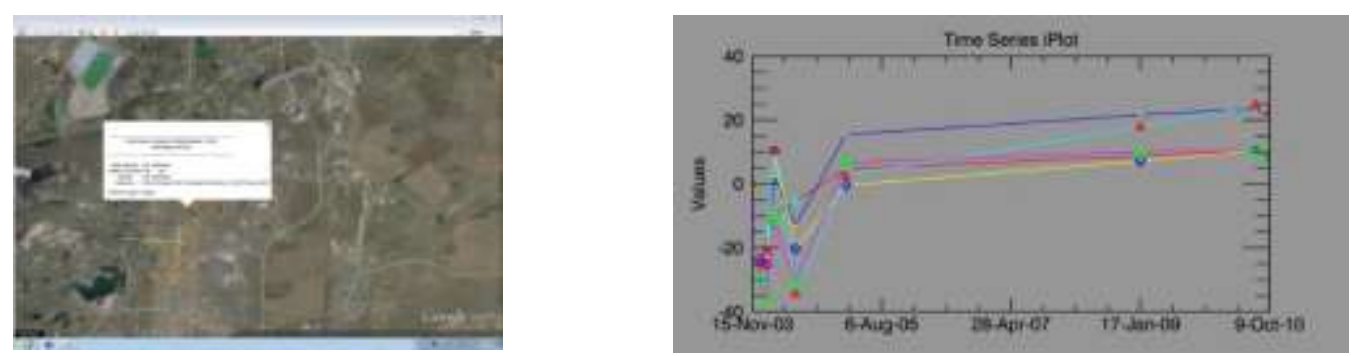

Photos taken in 2009-2010 made it possible to analyze events and accidents associated with the deformation and collapse of buildings and structures in the Karaganda region in 2011-2013 (Susan Smith, 2020).

Picture 9. Dams in Botakara settlement dynamics of the deformation process
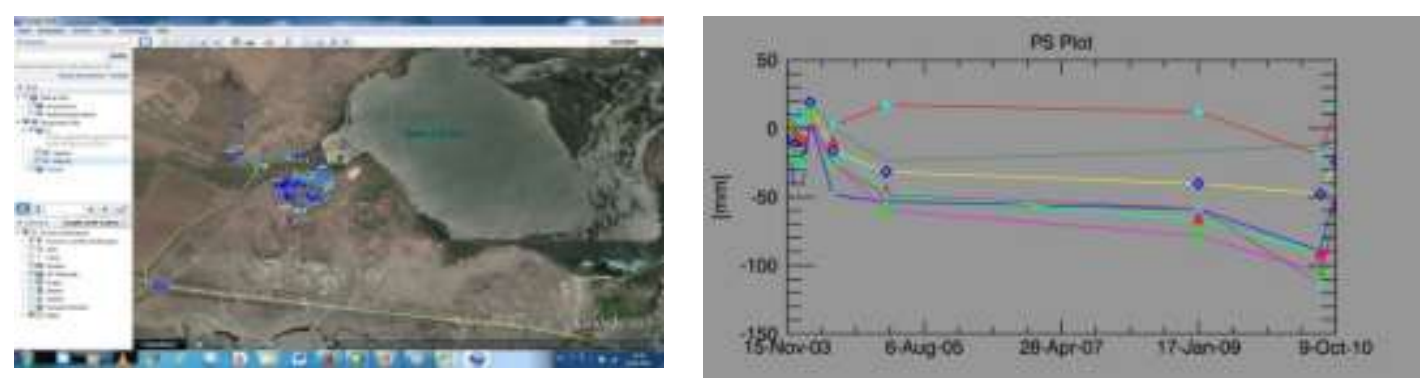
The results of the analysis of the plain in the area of the Kostenko mine show that since 2004 two sedimentary forms have appeared in the area of the Kostenko mine. In 2010, the amount of precipitation spreading increased (Picture 10). During the specified period, work was carried out at the Kostenko mine K1 on the seam and $45 \mathrm{~K} 1-\mathrm{z}$ on the longwall. The thickness of the exposed layer was $2.8 \mathrm{~m}$ (Kharchenko, 2017).

Picture 10. Creation of differentiated interferograms of Karaganda on different pairs of images
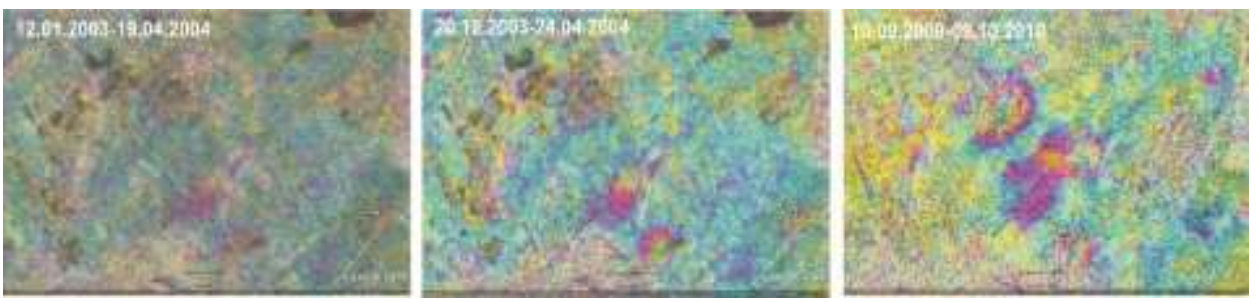

In addition, from 2003 to 2010, annual subsidence was observed in some areas of the Kostensky mine (Picture 11).

Picture 11. The territory of the mine Kostenko
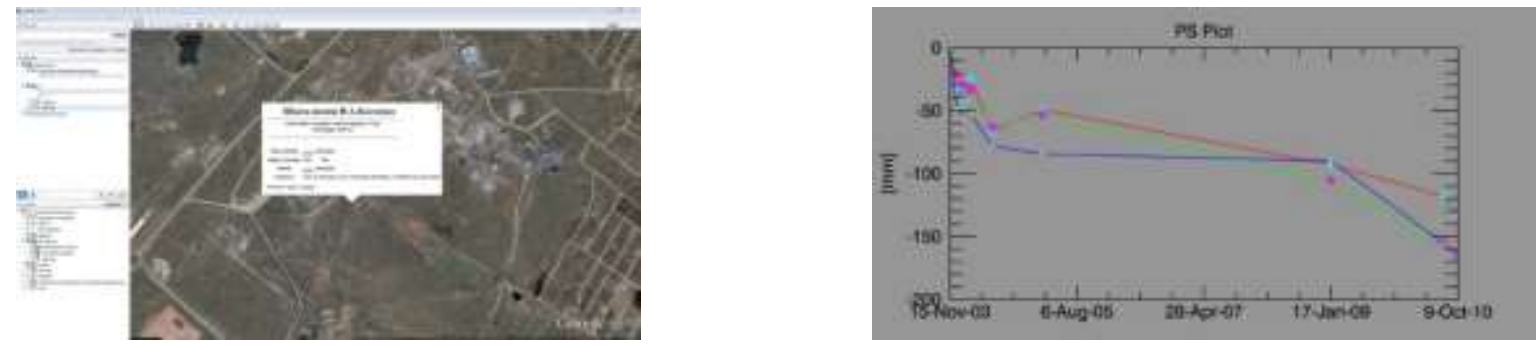

Analysis of the surface of the city of Shakhtinsk, where the operating Kazakhstanskaya mine is located, showed that accelerated subsidence occurred in 2009-2010 (Picture 12).

Picture 12. Mine territory Shakhtinskaya
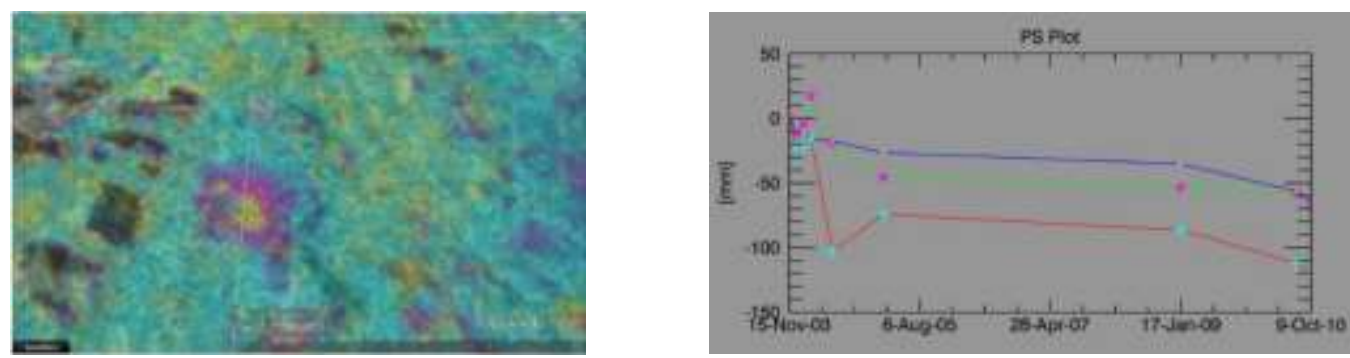

The data from the space probe coincided with the development plan of the Shakhtinskaya mine, which makes it possible to use the data from the space probe to monitor the development of the deposit, as well as to prevent dangerous deformations. Prediction of dangerous deformations is very important for this region, since the settlement of Severny is located not far from the mine (Susan Smith, 2020).

\section{Conclusions}

The results of the study showed that the method of satellite radar interferometry has a number of advantages over traditional methods of surveying and calculating when monitoring the movement of the surface of the treated areas. The results of the data on subsidence of the earth's surface showed good correlation and high measurement accuracy. Among the advantages of this method, it is worth noting the possibility of monitoring large areas by area and the clarity of the results obtained. All this allows us to 
propose the method of satellite radar interferometer for observing the movement of rock massifs as a reliable method for controlling subsidence and deformation.

Cite this article as: Alimzhanova A.; Kadylbekova Kh. (2021). Processing the results of space observation

Of the processed areas of Karaganda. Challenges of Science. Issue IV, 2021, pp. 5-11. https://doi.org/10.31643/2021.01

\section{References}

Kainz Wolfgang. (2019). Cartography and the others. Geo-spatial Information Science, 52-60. (in Eng.).

Morev, I. O.; Nezamov, V. I.; (2018). Application of aerospace surveys for monitoring settlements. KGAU. Conference. pp.17-23. http://www.kgau.ru/new/all/konferenc/konferenc/2018/a17.pdf

Tarasova, L.V.; (2019). Information technology used in remote monitoring. International Journal of Humanities and Natural Sciences, 172-175. https://elibrary.ru/item.asp?id=41388444

Kharchenko, V.M.; (2017). Fizicheskiye osnovy I technika akms metodov Stavropol Russia., 37-51 (in Russ.)

Susan Smith. (2020). GISCafe Industry Predictions for 2020, GISCafe Voice. 28-52 (in Eng.). 